\title{
Urinary Neutrophil Gelatinase-Associated Lipocalin in Type 1 and Type 2 Hepatorenal Syndrome and Its Correlation with Kidney Function
}

\author{
Lider Olmen Panggabean ${ }^{1}$, Gontar Alamsyah Siregar ${ }^{2}$, Dharma Lindarto ${ }^{3}$, \\ Masrul Lubis ${ }^{2}$

\begin{abstract}
${ }^{1}$ Department of Internal Medicine, Faculty of Medicine, Sumatera Utara University, Medan
${ }^{2}$ Division of Gastroenterohepatology, Department of Internal Medicine, Faculty of Medicine, Sumatera Utara University, Medan

${ }^{3}$ Division of Metabolic and Endocrinology, Department of Internal Medicine, Faculty of Medicine, Sumatera Utara University, Medan
\end{abstract}

Corresponding Author: Gontar Alamsyah Siregar

\begin{abstract}
Objective: To determine the difference in urinary Neutrophil Gelatinase-Associated Lipocalin (uNGAL) levels in type 1 and type 2 Hepatorenal Syndrome (HRS) and determine the correlation between urinary NGAL and kidney function and the degree of liver disease severity in HRS patients.

Methods: A total of 26 patients consisting of 13 patients in each group, both in type 1 and type 2 HRS at Adam Malik Hospital, Medan City, Indonesia. Urine samples were taken for NGAL examination using the ELISA method. A blood sample is used to assess kidney function. Liver disease severity was measured using the Childpugh score. Data were analyzed using statistical t-test independent and Pearson correlation test. A $p$ value less than 0.05 was applied to each statistical test as significant.

Result: Total subjects consisted of 18 men and 8 women, with a mean age $57.5 \pm 8.91$ years old. Hepatitis B virus was the most common etiology of liver cirrhosis in this study (53.8\%) and the most degree of liver disease severity was Childpugh C (65.4\%). Urinary NGAL levels in type 1 HRS is significantly higher than type 2 $(155.71 \pm 43.04$ vs $105.85 \pm 32.32 \mathrm{ng} / \mathrm{ml}, \mathrm{p}=$ $0.003)$. There was a positive correlation between uNGAL and serum creatinine $(\mathrm{r}=0.488, \mathrm{P}=$ $0.006)$. There was a positive correlation between uNGAL and Child-pugh score $(\mathrm{r}=0.466, \mathrm{P}=$ $0.008)$.
\end{abstract}

Conclusion: Urinary NGAL level in type 1 HRS is higher than type 2, there is a positive correlation between uNGAL and serum creatinine and Child-pugh score in HRS patients.

Keywords: Hepatorenal syndrome, urinary

NGAL, Liver cirrhosis, kidney function.

\section{INTRODUCTION}

HRS is a complication that often occurs in Liver cirrhosis. Gines et al. reported the incidence of HRS in liver cirrhosis patients reaching $18 \%$ in the first year and will increase to $39 \%$ by the fifth year. ${ }^{[1]}$ A study conducted by Salerno et al. on liver cirrhosis patients with ascites at 21 hospitals in Italy found that the prevalence of HRS was around between $13-45.8 \%$. ${ }^{[2]}$ A study conducted by Martin-Llahi et al in patients with Liver cirrhosis found that the prevalence of HRS was $13 \%$. $^{[3]}$

HRS is a specific form of acute kidney injury (AKI) that occurs in cirrhosis. Serum creatinine has limitations in distinguishing the types of AKI that occur in cirrhosis. One of the points on the International Ascites Club (IAC) criteria for the diagnosis of HRS is that it takes 48 hours to assess whether there is improvement in serum creatinine or not after diuretic administration and volume 
expansion with albumin. This can delay therapy of the HRS itself and exacerbate portal hypertension. ${ }^{[4,5]}$

Due to the limitation of serum creatinine in diagnosing HRS, a new biomarker is needed that can quickly differentiate HRS from other AKI in liver cirrhosis patients, one of which is uNGAL. NGAL is a protein with $25 \mathrm{kD}$ molecular weight bound to gelatinase from neutrophil cells. ${ }^{[6]}$ NGAL is produced in the distal nephron (thick ascending limb of Henle's loop, distal tubule, collecting tubule) and its production increases in response to renal injury. ${ }^{[7,8]}$ The increase in NGAL concentration was faster than the increase in serum creatinine in AKI conditions. NGAL is also more sensitive to the presence of tissue damage than functional disorders so that it can distinguish structural or functional disorders. ${ }^{[9]}$

Previous studies have reported that uNGAL can be useful in differentiating between HRS and other AKI that occur in HRS, this is because the level is significantly different from other AKI. ${ }^{[10-14]}$

Meanwhile, studies comparing uNGAL levels between type 1 and type 2 HRS are still rare. There are still differences in several previous studies regarding the uNGAL levesl for each type of HRS. Research conducted by El-Bassat et al. concluded that there was a significant difference in uNGAL values between type 1 and type 2 HRS. $^{[13]}$ Meanwhile, other studies reported no significant difference between uNGAL levels for the two types of HRS. ${ }^{10}$ For this reason, this study was conducted to see how the difference in uNGAL levels between types 1 and type 2 HRS and to see the correlation between uNGAL and kidney function and the degree of liver disease severity in liver cirrhosis patients with HRS.

\section{METHODS}

\section{Study design}

This study was a cross-sectional study conducted at Adam Malik Hospital, Medan city, Indonesia and Network
Hospital after obtaining approval from the University of North Sumatera Medical Research Ethics Commission / Adam Malik Hospital. The research time was carried out from May to December 2020.

\section{Study subject}

The research subjects were liver cirrhosis patients with HRS who came to the Adam Malik Hospital and Network Hospital between May - December 2020. Then these patients were grouped into the type 1 or type 2 HRS group until the number of samples was met. The diagnosis of HRS was made using the revised International Ascites Club (IAC) 2007 criteria. Patients <18 years old, pregnant women, suffering from systemic disease, sepsis, malignancy, previous history of kidney disease, and refusal to participate were excluded from this study.

Based on the IAC criteria, HRS is enforced if there is a condition, namely liver cirrhosis with ascites, Serum creatinine $>1.5$ $\mathrm{mg} / \mathrm{dl}(133 \mu \mathrm{mol} / \mathrm{L})$, no improvement in serum creatinine (decrease to level of $<1.5$ $\mathrm{mg} / \mathrm{dl}$ ) at least 2 days after diuretic administration and volume expansion with albumin, no shock and use nephrotoxic drugs, no renal parenchymal disease characterized by proteinuria $>500 \mathrm{mg} / \mathrm{day}$, microhematuria $>50$ red blood cells/high power field, and/or abnormal ultrasound. Type 1 HRS is HRS with progressive decline in renal function, with serum creatinine> $2.5 \mathrm{mg} / \mathrm{dl}$ at the time of examination and/or a 2-fold increase over 2 weeks. Type 2 HRS is HRS with a moderate and stable decline in renal function, with serum creatinine between 1.5 to $2.5 \mathrm{mg} /$ dl). ${ }^{[4]}$

Kidney function was measured by examining serum ureum and creatinine and calculating glomerular filtration rate (GFR) using formula Cockcroft and Gault. Liver disease severity was assessed using the Child-pugh score.

\section{Biochemical Analysis}

Patients who were included in the type 1 and type 2 HRS groups were 
subjected to a urine NGAL examination. The middle portion of urine (spot urine) is collected at least $30 \mathrm{cc}$, then measurements are taken using commercial NGAL (Quantikine ELISA; Human Lipocalin-2 / NGAL Immunoassay, R\&D System Inc). Demographic and biochemical data including complete blood count, kidney function, liver function, hematologic function, albumin, electrolytes were collected when the patient was admitted to the hospital. The Child-pugh score was calculated using clinical and laboratory data when the patient was admitted.

\section{Statistical analysis}

Data is presented descriptively, by displaying the frequency distribution and percentage for categorical data. Meanwhile, numerical data is presented by displaying data mean and standard deviation. The data normality test used the Shapiro Wilk test. To determine the difference in uNGAL levels between type 1 and type 2 HRS, an independent t-test was used, while the correlation between UNGAL with renal function and child-pugh score were assessed using the Pearson correlation test. Data analysis used the SPSS 22 (Statistical Product and for Social Sciences) computer program and a 95\% confidence interval, where $p<0.05$ was statistically significant.

\section{RESULTS}

Table 1. Characteristics of patients
\begin{tabular}{|l|l|}
\hline Characteristics & with HRS \\
\hline Gender, $\mathrm{n}(\%)$ & $18(69.2 \%)$ \\
Men & $8(30.8 \%)$ \\
Women & $57.5 \pm 8.91$ \\
\hline Age (years), mean \pm SD & $59.04 \pm 5.99$ \\
\hline Body weight (kg), mean \pm SD & \\
\hline Etiology of cirrhosis, n (\%) & $14(53.8 \%)$ \\
Hepatitis B & $1(3.9 \%)$ \\
Hepatitis C & $11(42.3 \%)$ \\
Others & \\
\hline Child-pugh classification, n (\%) & - \\
A & $9(34.6 \%)$ \\
B & $17(65.4 \%)$ \\
C & \\
\hline
\end{tabular}

The total study subjects were 26 patients consisting of 13 patients in each of the type 1 and type 2 HRS groups. Most of the sexes were male, amounting to 18 patients $(69.2 \%)$, with an average age of
57.5 years old. The most common etiology of liver cirrhosis was hepatitis B virus as many as 14 patients $(53.8 \%)$ with the highest degree of liver severity being childpugh $\mathrm{C}$ as many as 17 patients $(65.4 \%)$ as shown in Table 1.

Based on the type of HRS, the most data were male, both in type 1 and type 2 HRS. The most common etiology of cirrhosis in type $1 \mathrm{HRS}$ was other causes (other than hepatitis B and C) by 8 patients $(61.5 \%)$ and in type 2 HRS, the most common cause of cirrhosis was hepatitis B with 10 patients $(76.9 \%)$. The highest degree of liver disease severity in both type 1 and type 2 HRS was child-pugh $\mathrm{C}$ as shown in table 2 .

Table 2. Characteristics of samples by type of HRS

\begin{tabular}{|l|l|l|}
\hline \multirow{2}{*}{ Characteristics } & HRS \\
\cline { 2 - 3 } & $\begin{array}{l}\text { Type 1 HRS } \\
(\mathrm{n}=13)\end{array}$ & $\begin{array}{l}\text { Type 2 HRS } \\
(\mathrm{n}=13)\end{array}$ \\
\hline $\begin{array}{l}\text { Gender, n (\%) } \\
\text { Men }\end{array}$ & $\begin{array}{l}9(69.2 \%) \\
4(30.8 \%)\end{array}$ & $\begin{array}{l}9(69.2 \%) \\
4(30.8 \%)\end{array}$ \\
Women & $57.54 \pm 7.18$ & $57.46 \pm 10.68$ \\
\hline Age (years), mean \pm SD & $56.31 \pm 5.46$ & $61.77 \pm 5.35$ \\
\hline Body weight (kg), mean \pm SD & & \\
\hline Etiology of cirrhosis, n (\%) & $4(30.8)$ & $10(76.9)$ \\
Hepatitis B & $1(7,7)$ & - \\
Hepatitis C & $8(61.5)$ & $3(23.1)$ \\
Others & & \\
\hline Child-pugh classification, $\mathrm{n}(\%)$ & - & - \\
A & $4(30.8)$ & $5(38.5)$ \\
B & $9(69.2)$ & $8(61.5)$ \\
C & $10.38 \pm 1.38$ & $9.85 \pm 1.34$ \\
Score & &
\end{tabular}

Table 3. Characteristics of laboratory results

\begin{tabular}{|c|c|c|c|}
\hline \multirow{2}{*}{$\begin{array}{l}\text { Laboratory } \\
\text { Characteristics }\end{array}$} & \multicolumn{3}{|l|}{ HRS } \\
\hline & $\begin{array}{l}\text { Type } 1 \text { HRS } \\
(\mathrm{n}=13)\end{array}$ & $\begin{array}{l}\text { Type } 2 \text { HRS } \\
(\mathrm{n}=13)\end{array}$ & $\begin{array}{l}P \\
\text { value }\end{array}$ \\
\hline $\mathrm{Hb}$ & $8.63 \pm 1.13$ & $9.45 \pm 1.17$ & $0.085^{\mathrm{a}}$ \\
\hline Leukocytes & $\begin{array}{l}6550 \\
(3620-12340)\end{array}$ & $\begin{array}{l}9470 \\
(4940-12220)\end{array}$ & $0.166^{b}$ \\
\hline Platelets & $130769 \pm 48499$ & $140384 \pm 48977$ & $0.620^{\mathrm{a}}$ \\
\hline $\mathrm{Na}$ & $129.77 \pm 9.23$ & $131.85 \pm 7.15$ & $0.527^{\mathrm{a}}$ \\
\hline $\mathrm{K}$ & $3.9(3,1-7)$ & $4.7(3,4-6,9)$ & $0.090^{b}$ \\
\hline $\mathrm{Cl}$ & $102(75-107)$ & $101(81-106)$ & $0.502^{b}$ \\
\hline Ureum & $93.01 \pm 27.28$ & $75.55 \pm 38.73$ & $0.196^{\mathrm{a}}$ \\
\hline Creatinine & $2.99 \pm 0.28$ & $1.91 \pm 0.26$ & $0.001^{\mathrm{a}}$ \\
\hline GFR & $20.69 \pm 3.56$ & $36.38 \pm 8.70$ & $0.001^{\mathrm{a}}$ \\
\hline Albumin & $2.52 \pm 0.62$ & $2.80 \pm 0.65$ & $0.268^{\mathrm{a}}$ \\
\hline Total bilirubin & $3.1(0.9-25.5)$ & $3.1(0.5-13.4)$ & $0.663^{b}$ \\
\hline SGOT & $87(23-328)$ & $76(13-325)$ & $0.538^{b}$ \\
\hline SGPT & $54(22-128)$ & $49(18-196)$ & $1^{\mathrm{b}}$ \\
\hline INR & $1.62 \pm 0.48$ & $1.46 \pm 0.39$ & $0.363^{\mathrm{a}}$ \\
\hline
\end{tabular}

Table 3 shows the laboratory results of both type 1 and type 2 HRS groups. There were no significant differences from the laboratory parameters of the two groups 
except for renal function parameters, where there was a significant difference in serum creatinine levels between type 1 and type 2 HRS $(2.99 \pm 0.28$ vs $1.91 \pm 0.26 ; p<0.001)$ and also the GFR values $(20.69 \pm 3.56$ vs $36.38 \pm 8.70 ; \mathrm{p}<0.001)$.

There is a significant difference in uNGAL levels between type 1 and type 2 HRS, where the average uNGAL level on type $1 \mathrm{HRS}$ was $155.71 \pm 43.04 \mathrm{ng} / \mathrm{ml}$ and the average uNGAL level on type $2 \mathrm{HRS}$ was $105.85 \pm 32.32 \mathrm{ng} / \mathrm{ml}$, with $p$ value $=$ 0.003 as shown in table 4 .

Table 4. Urinary NGAL levels for type 1 and type 2 HRS

\begin{tabular}{|l|l|l|}
\hline HRS & Urinary NGAL $(\mathbf{n g} / \mathbf{m l})$ & P value \\
\hline Type 1 HRS & $155.71 \pm 43.04$ & $0.003 *$ \\
\cline { 1 - 2 } Type 2 HRS & $105.85 \pm 32.32$ & \\
\hline \multicolumn{3}{|c|}{$* p<0.05$ (significant) }
\end{tabular}

Table 5 shows that there is a positive correlation between the uNGAL and serum creatinine $(\mathrm{r}=0.488, \quad \mathrm{P}=0.006)$. Meanwhile, there was a negative correlation between the uNGAL and GFR $(\mathrm{r}=-0.338, \mathrm{P}$ $=0.046)$. Meanwhile, there was no correlation between urea and uNGAL $(\mathrm{r}=$ $0.235, \mathrm{P}=0.124)$. In terms of liver disease severity, there was a positive correlation between uNGAL and the Child-Pugh score $(r=0.466 ; P=0.008)$.

Table 5. Relationship between uNGAL levels and kidney function and liver disease severity

\begin{tabular}{|l|l|l|}
\hline \multirow{2}{*}{} & \multicolumn{2}{|l|}{ Urinary NGAL levels } \\
\cline { 2 - 3 } & $\boldsymbol{r}$ & $\boldsymbol{P}$ value \\
\hline Serum creatinine & 0.488 & $0.006^{*}$ \\
\hline Ureum & 0.228 & 0.131 \\
\hline GFR & -0.338 & $0.046^{*}$ \\
\hline Child-pugh score & 0.466 & $0.008 *$ \\
\hline \multicolumn{2}{|l}{ * Pearson correlation }
\end{tabular}

\section{DISCUSSION}

Previous studies have reported that urinary NGAL can differentiate between HRS and other AKIs that occur in cirrhosis. This is because in HRS there is an increase in urinary NGAL level in the intermediate range, which is significantly different from pre-renal azotemia and acute tubular necrosis (ATN). ${ }^{[10-14]}$ The mechanism of increased NGAL in HRS patients is still unclear, it was previously known that HRS is a functional renal impairment, not a structural one. ${ }^{[15]}$ However pathological investigations have reported minor tubular and glomerular damage in the kidneys of HRS patients, some seen only with electron microscopy. ${ }^{[16,17]}$ This may be due to cellular changes associated with chronic activation of angiotensin-aldosteron system. [18] It is conceivable that deep vascular constriction of the renal vascular causes subclinical tubular damage to at least a subset of nephron, which is undetectable by urine sodium which is not sensitive enough to detect mild or patchy tubular epithelial damage. This is supported by Cavallin et al, who reported that type 1 HRS was not completely functional, but was also associated with renal tubular damage. ${ }^{[19]}$ The subclinical tubular damage caused an increase in level of UNGAL in HRS patients.

In this study it was found that the uNGAL level in type 1 HRS was significantly higher than type $2 \mathrm{HRS}$. These results are consistent with the research conducted by El-Bassat et al and Fagundez et al, but differ from the results obtained by Gungor et al. ${ }^{[10,11,13]}$ More severe and profound renal vasoconstriction in type 1 HRS may be the cause of higher uNGAL values in type 1 HRS compared to type 2 HRS. $^{[12]}$

The results of this study are in line with those reported El-Bassat and Gungor that there is a positive correlation between uNGAL and serum creatinine and negative correlation with GFR. This shows that the higher level of UNGAL, the worse kidney function will be. Several previous studies have also reported that an increase in NGAL level precedes an increase in serum creatinine in the event of AKI.

The results of the study also showed that there was a positive correlation between uNGAL and the degree of liver disease severity as indicated by the Child-pugh score. Based on the pathophysiology, HRS occurs due to the presence of portal hypertension which results in a decrease in effective arterial volume so that the body responds with activation of the neurohumoral system (RAAS, SNS, ADH) which will cause renal vasoconstriction 
resulting in HRS. ${ }^{[23-27]}$ So that HRS usually occurs in conditions of severe liver disease, a study by Garcia-Tsao et al. reported that HRS occurs in advanced liver disease with high mean child-pugh scores. ${ }^{[28]}$

\section{CONCLUSION}

Urinary NGAL levels in type $1 \mathrm{HRS}$ was significantly higher than type 2 HRS, possibly because of more severe renal vasoconstriction occurring in type 1 HRS. There is a positive correlation with moderate strength between uNGAL levels with serum creatinine and child-pugh scores, as well as a negative correlation with weak strength between uNGAL levels and GFR in HRS patients.

\section{ACKNOWLEDGEMENT}

The authors gratefully acknowledge that the present research is supported by the Ministry of Research and Technology and Higher Education Republic of Indonesia. The support is under the research grant DRPM (Direktorat Riset dan Pengabdian Masyarakat).

\section{Conflict of Interest: None}

\section{Source of Funding: None}

\section{Ethical Approval: Approved}

\section{REFERENCES}

1. Ginès $\mathrm{A}$, Escorsell $\mathrm{A}$, Ginès $\mathrm{P}$, Saló $\mathrm{J}$, Jiménez $\mathrm{W}$, Inglada $\mathrm{L}$ et al. Incidence, predictive factors, and prognosis of the hepatorenal syndrome in cirrhosis with ascites. Gastroenterology. 1993;105(1):229236.

2. Salerno F, Cazzaniga M, Merli M, Spinzi G, Saibeni S, Salmi A et al. Diagnosis, treatment and survival of patients with hepatorenal syndrome: A survey on daily medical practice. Journal of Hepatology. 2011;55(6):1241-1248.

3. Martín-Llahí M, Guevara M, Torre A, Fagundes C, Restuccia T, Gilabert R et al. Prognostic Importance of the Cause of Renal Failure in Patients With Cirrhosis. Gastroenterology. 2011;140(2):488-496.
4. Salerno F, Gerbes A, Gines P, Wong F, Arroyo V. Diagnosis, prevention and treatment of hepatorenal syndrome in cirrhosis. Gut. 2007;56(9):1310-1318.

5. Cholongitas E, Shusang V, Marelli L, Nair $\mathrm{D}$, Thomas M, Patch D, et al. Review article: renal function assessment in cirrhosis - difficulties and alternative measurement. Alimentary Pharmacology \& Therapeutics. 2007;26(7):969-978.

6. Cai L, Rubin J, Han W, Venge P, Xu S. The origin of multiple molecular forms in urine of HNL / NGAL. Clinical Journal of the American Society of Nephrology. 2010; 5(12):2229-2235.

7. Schmidt-Ott KM. Neutrophil gelatinaseassociated lipocalin as a Biomarker of Acute kidney Injury - Where do we stand today?. Nephrology Dialysis Transplantation. 2011; 26(3):762-764.

8. Devarajan P. Neutrophil gelatinaseassociated lipocalin (NGAL): A new marker of kidney disease. Scandinavian Journal of Clinical and Laboratory Investigation. 2008; 241:89-94.

9. Singer E, Elger A, Elitok S, Kettritz R, Nickolas TL, Barasch J, et al. Urinary neutrophil gelatinase-associated lipocalin distinguishes pre-renal from intrinsic renal failure and predicts outcomes. Kidney International. 2011;80(4): 405-414.

10. Gungor G, Ataseven H, Demir A, Solak Y, Gaipov A, Biyik M, al. Neutrophil gelatinase-associated lipocalin in prediction of mortality in patients with hepatorenal syndrome: a prospective observational study. Liver International. 2014;34(1): 4957.

11. Fagundes C, Pepin M, Guevara M, Barreto P, Casals G, Sola E, et al. 2012. Urinary neutrophil gelatinase-associated lipocalin as a Biomarker in the Differential Diagnosis of Impairment of Kidney Function in Cirrhosis. Journal of Hepatology. 2012;57(2): 267-73.

12. Verna E, Brown R, Farrand E, Pichardo E, Forster C, Sola-Del Valle D et al. Urinary Neutrophil Gelatinase-Associated Lipocalin Predicts Mortality and Identifies Acute Kidney Injury in Cirrhosis. Digestive Diseases and Sciences. 2012;57(9):23622370.

13. Ziada D, Alm-Eldin R, El-Bassat H, Taha A. Urinary neutrophil gelatinase-associated lipocalin as a biomarker for the diagnosis of 
hepatorenal syndrome in cirrhotic patients. Tanta Medical Journal. 2013;41(4):346-352.

14. Hamdy H, El-Ray A, Salaheldin M, Lasheen M, Aboul-Ezz M, Abdel-Moaty A et al. Urinary Neutrophil GelatinaseAssociated Lipocalin in Cirrhotic Patients with Acute Kidney Injury. Annals of Hepatology. 2018;17(4):624-630.

15. I Dewa NW. Hepatorenal Syndrome. In: Textbook of Liver Disease, First Revised Edition. Jakarta: Sagung Seto; 2012. P 401411.

16. Mandal AK, Landing M, Fahmy A. Acute tubular necrosis in hepatorenal syndrome: an electron microscopy study. American Journal of Kidney Disease. 1982;2(3): 363374.

17. Kanel GC, Peters RL. Glomerular tubular reflux - a morphologic renal lesion associated with hepatorenal syndrome. Hepatology. 1984;4(2): 242-246.

18. Hollenburg NK. Aldosterone in the development and progression of renal injury. Kidney International. 2004;66(1): 19.

19. Cavallin M, Fasolato S, Sticca A, Gola E, Bortoluzzi A, Morando F et al. F-50 Increased urinary level of neutrophil gelatinase-associated lipocalin (NGAL) in patients with cirrhosis and type 1 HRS. Digestive and Liver Disease. 2012;44(1):S47-S48.

20. Haase M, Devarajan P, Haase-Fielitz A, Bellomo R, Cruz D, Wagener $G$ et al. The Outcome of Neutrophil GelatinaseAssociated Lipocalin-Positive Subclinical Acute Kidney Injury. Journal of the American College of Cardiology. 2011; 57(17):1752-1761.

21. Wagener G, Jan M, Kim M, Mori K, Barasch J, Sladen $\mathrm{R}$ et al. Association between Increases in Urinary Neutrophil Gelatinase-associated Lipocalin and Acute Renal Dysfunction after Adult Cardiac Surgery. Anesthesiology. 2006;105(3):485491.
22. Mishra J, Ma Q, Prada A, Mitsnefes M, Zahedi $\mathrm{K}$, Yang $\mathrm{J}$, et al. Identification of neutrophil gelatinase associated lipocalin as a novel early urinary biomarker for ischemic renal injury. Journal of the American Society of Nephrology. 2003;14(10): 25342543.

23. Low G, Alexander G, Lomas D. Hepatorenal Syndrome: Aetiology, Diagnosis, and Treatment. Gastroenterology Research and Practice. 2015;2015: 1-11.

24. Albillos A, Lario M, Alvarez-Mon M. Cirrhosis-associated immune dysfunction: distinctive features and clinical relevance. Journal of Hepatology. 2014;61(6): 13851396.

25. Bernanrdi M, Moreau R, Angeli P, Schnabl B, Arroyo V. Mechanism of decompensation and organ failure in cirrhosis: from peripheral arterial vasodilation to systemic inflammation hypothesis. Journal of Hepatology. 2015; 63(5): 1272-1284.

26. Solé C, Solà E, Morales-Ruiz M, Fernàndez G, Huelin P, Graupera I et al. Characterization of Inflammatory Response in Acute-on-Chronic Liver Failure and Relationship with Prognosis. Scientific Reports. 2016;6(1).

27. Ginès P, Solà E, Angeli P, Wong F, Nadim M, Kamath P. Hepatorenal syndrome. Nature Reviews Disease Primers. 2018;4(1): 23.

28. Garcia-Tsao G, Parikh CR, Viola A. Acute kidney injury in cirrhosis. Hepatology. 2008;48(6): 2064-2077.

How to cite this article: Panggabean LO, Siregar GA, Lindarto D et.al. Urinary neutrophil gelatinase-associated lipocalin in type 1 and type 2 hepatorenal syndrome and its correlation with kidney function. International Journal of Research and Review. 2021; 8(7): 359-364. DOI: https://doi.org/10.52403/ijrr.20210750 